\title{
Survival after burn in a sub-Saharan burn unit: Challenges and opportunities
}

\author{
Anna F. Tyson ${ }^{\mathrm{a}}$, Laura P. Boschini ${ }^{\mathrm{a}}$, Michelle M. Kiser ${ }^{\mathrm{a}}$, Jonathan C. Samuel ${ }^{\mathrm{a}, \mathrm{b}, \mathrm{c}}$, Steven N. \\ Mjuweni $^{\mathrm{b}}$, Bruce A. Cairns ${ }^{\mathrm{b}, \mathrm{c}}$, and Anthony G. Charles ${ }^{\mathrm{a}, \mathrm{b}, \mathrm{c},{ }^{*}}$ \\ aDepartment of Surgery, University of North Carolina, United States \\ bDepartment of Surgery, Kamuzu Central Hospital, Lilongwe, Malawi \\ 'North Carolina Jaycee Burn Center, Chapel Hill, United States
}

\section{Abstract}

Background-Burns are among the most devastating of all injuries and a major global public health crisis, particularly in sub-Saharan Africa. In developed countries, aggressive management of burns continues to lower overall mortality and increase lethal total body surface area (TBSA) at which 50\% of patients die (LA50). However, lack of resources and inadequate infrastructure significantly impede such improvements in developing countries.

Methods-This study is a retrospective analysis of patients admitted to the burn center at Kamuzu Central Hospital in Lilongwe, Malawi between June 2011 and December 2012. We collected information including patient age, gender, date of admission, mechanism of injury, time to presentation to hospital, total body surface area (TBSA) burn, comorbidities, date and type of operative procedures, date of discharge, length of hospital stay, and survival. We then performed bivariate analysis and logistic regression to identify characteristics associated with increased mortality.

Results-A total of 454 patients were admitted during the study period with a median age of 4 years (range 0.5 months to 79 years). Of these patients, $53 \%$ were male. The overall mean TBSA was $18.5 \%$, and average TBSA increased with age-17\% for 0-18 year olds, $24 \%$ for $19-60$ year olds, and $41 \%$ for patients over 60 years old. Scald and flame burns were the commonest mechanisms, $52 \%$ and $41 \%$ respectively, and flame burns were associated with higher mortality. Overall survival in this population was $82 \%$; however survival reduced with increasing age categories (84\% in patients $0-18$ years old, $79 \%$ in patients $19-60$ years old, and $36 \%$ in patients older than 60 years). TBSA remained the strongest predictor of mortality after adjusting for age and mechanism of burn. The LA50 for this population was 39\% TBSA.

Discussion-Our data reiterate that burn in Malawi is largely a pediatric disease and that the high burn mortality and relatively low LA50 have modestly improved over the past two decades. The lack of financial resources, health care personnel, and necessary infrastructure will continue to pose a significant challenge in this developing nation. Efforts to increase burn education and prevention in addition to improvement of burn care delivery are imperative.

(C) 2013 Elsevier Ltd and ISBI. All rights reserved.

*Corresponding author at: UNC School of Medicine, University of North Carolina, 4008 Burnett Womack Building, CB 7228, United States., Tel.: +1 919966 4389; fax: +1 919 9660369., anthchar@med.unc.edu.

Conflict of interest statement

All authors have no conflict of interest to disclose. 


\section{Keywords}

Burns; Injury; Sub-Saharan Africa; Malawi; LA50; Lethal dose total body surface area

\section{Introduction}

Burns are among the most devastating of all injuries and a major global public health crisis $[1,2]$. Burns are the fourth most common type of trauma worldwide, following traffic accidents, falls, and interpersonal violence [3]. An estimated 195,000 deaths occur each year from fires alone, and fire-related deaths alone rank among the 15 leading causes of death among children and young adults 5-29 years of age [4].

Burn units in high-income countries demonstrate a low overall mortality and high LA50, defined as the TBSA burn at which 50\% of patients die. In the 1940s, LA50 in the United States was $40 \%$ [5]. With the development of broad-spectrum antibiotics and specialized burn units, LA50 increased to approximately $60 \%$ in the 1970s [6]. Epidemiologic studies from developed countries have reported that the survival rates for burn patients have continued to improve substantially over the past four decades because of advances in burn management, particularly in the area of fluid resuscitation, early nutritional supplementation, pulmonary care, wound nursing, and infection control [7-9]. Currently, most burn centers in the United States report LA50 over 90\% [6]. Europe experienced a similar improvement in LA50 over time. Wasserman and Schlotterer [10] showed an overall mortality of $11.8 \%$ and LA50 of 60\% in 1985 in France. In 1999, Barrett et al. demonstrated an overall mortality of $3.5 \%$ and LA50 of $90 \%$ in Spain [11].

Unfortunately, the vast majority of burns occur in low- and middle-income countries (LMICs), regions that generally lack the necessary infrastructure to reduce the incidence and severity of burns [12]. Globally, Africa has the second highest rate of fatal burns and is responsible for $15 \%$ of global fire-related mortality [13]. However, given the paucity of burn related data in sub-Saharan Africa, the true burden of burn is likely grossly underestimated [14]. As there are relatively few epidemiologic studies assessing burn treatment and survival in LMICs, the primary objective of this study is to examine data from a burn registry database in central Malawi and identify factors associated with increased mortality.

\section{Methods}

This study is a retrospective analysis of prospectively collected burn registry data at Kamuzu Central Hospital $(\mathrm{KCH})$, a 600-bed tertiary care hospital in the capital city of Lilongwe, which serves as a referral center for approximately 5 million people in the central region of Malawi. The University of North Carolina Institutional Review Board and the Malawi National Health Sciences Review Committee approved this study. The burn unit at KCH was established in 2011 and averages 25-40 admissions per month [15]. Pediatric and adult patients are admitted to the same unit, which consists of 31 beds, 10 full-time nurses, and 2 trained clinical officer staff with surgical oversight. The burn registry was established to collect patient demographic and clinical characteristics in addition to outcome. Specifically, data points utilized in this study include age, sex, date of admission, mechanism of injury, time to presentation to hospital, TBSA burn, comorbidities, date and type of operative procedures, length of hospital stay, and outcome (survived to discharge/died). All patients admitted between June 2011 and December 2012 were included in this analysis.

We performed bivariate analysis to compare variables based on mortality outcome and logistic regression modeling to determine predictors of mortality. Odds of mortality for increasing TBSA was calculated using a Logit TBSA dose response model, and LA50 
determination was based on the TBSA burns that increased by a geometrical progression. All statistical analysis was performed using Stata/SE 12.1 (Stata-Corp LP, College Station, TX).

\section{Results}

A total of 454 patients were admitted and treated during the study period with a median age of 4 years (range 0.5 months to 79 years) and a slight male preponderance of $53 \%$. The majority of our patients were in the pediatric age range with $73 \%$ being younger than 10 years old. Only 17 patients in this cohort were older than 50 years old (Table 1). Patient age distribution was similar between sexes. Scald and flame burns were the most common etiologies, making up 52\% and $41 \%$ respectively. The average TBSA in this cohort was $18.5 \%$ (SD \pm 17.4 ) (Fig. 1). TBSA did not differ significantly between sexes, but did show considerable difference between age groups. The average TBSA was $17 \%$ for $0-18$ year olds, $24 \%$ for $19-60$ year olds, and $41 \%$ for patients more than 60 years old (Table 1).

Collecting data on intravenous fluid resuscitation and operative procedures assessed management of the burn patients in our unit. Intravenous fluids, when indicated, were correctly ordered in $53.5 \%$ of patients and incorrectly ordered or administered in $8.4 \%$ (Table 2). Of the 454 patients in this cohort, 169 underwent at least one operative procedure (37.2\%) and 99 patients required more than one operative procedure $(21.8 \%)$. The number of operative interventions per patient is illustrated in Fig. 2. No statistically significant difference was found between the number of operative procedures performed and patient survival (Table 3). The commonest procedures were skin grafting and debridement, accounting for $46.7 \%$ and $42.8 \%$ of all operative cases, respectively (Table 2). Other operative procedures included escharotomy, amputation, trepanation, and contracture release.

Most patients presented to the hospital within $24 \mathrm{~h}$ of injury (62\%), although $31 \%$ experienced a delay greater than $48 \mathrm{~h}$. In general, patients who presented to the hospital within $6 \mathrm{~h}$ of injury had higher mortality than patients who presented later, although the difference was not statistically significant for all categories (Table 3 ). The average time from admission to first procedure was 12.8 days (range $0-70$ days), and most patients requiring an operation were taken to the operating room within 20 days of admission (Fig. 3 ). Both time to first procedure and overall length of stay were lower for patients who died.

Most burn related mortality occurred within 10 days of admission, which likely indicates death from shock due to overwhelming burn or under-resuscitation by inadequate fluid administration or delayed presentation. Late deaths are more likely a result of burn wound sepsis and multiorgan failure occurring during the hospital course. In the absence of cause of death data, however, we cannot confirm these assumptions.

Very few patients had recorded comorbidities $(n=56)$. Of these, 46 had a diagnosis of epilepsy, five had documented malnutrition, and five had other comorbidities, including pneumonia, pregnancy, eclampsia, and psychiatric illness. Overall, the presence of documented comorbidities was not statistically associated with increased mortality.

During the study period, overall survival was $82.2 \%$. As expected, mortality was significantly higher in elderly patients. Survival was $84 \%$ for $0-18$ year olds and dropped to $36 \%$ for patients greater than 60 years old. Males showed a non-statistically significant higher mortality compared to females with $20 \%$ and $16 \%$ mortality respectively $(p=0.3)$. Flame burns were associated with higher mortality than scald burns $(p<0.001)$. TBSA was also significantly associated with mortality, as expected. The average TBSA for patients 
who survived was $14 \%$, while the average TBSA in patients who died was $39 \%(p<0.001)$. Characteristics associated with increased mortality are summarized in Table 3.

LA50 was calculated by performing a logistic regression of survival by TBSA. The unadjusted LA50 for this population was $38.5 \%$ TBSA. The odds of mortality were 2.43 for every $10 \%$ increase in TBSA. The logistic regression was then repeated, adjusting for age and mechanism of burn; other potentially confounding variables, such as sex and presence of comorbidities, did not significantly alter the regression and were therefore dropped from the model. Since this cohort included very few patients with burns greater than $60 \%$ TBSA, we limited the logistic regression to TBSA $<60 \%$, in order to more accurately predict the LA50. The adjusted regression model estimated a LA50 of 39\% (Fig. 4).

\section{Discussion}

Burns make up 5.6\% of all injuries and $11.1 \%$ of all pediatric injuries treated at $\mathrm{KCH}$; approximately $26 \%$ of all burn patients seen in the emergency department are admitted to the hospital [16,17]. Prior to the establishment of the burn unit, the average TBSA was $14 \%$ and overall mortality was $27 \%$. Intravenous fluid resuscitation was often inadequate and one-third of patients developed wound infections [20]. Within two years of the establishment of a burn unit at $\mathrm{KCH}$, intravenous fluids are appropriately administered in greater than $50 \%$ of patients and overall mortality is less than $20 \%$.

The data from our burn unit are consistent with findings in other burn centers in sub-Saharan Africa and are reflective of the poor burn survival in the region [18,19]. Burn in Malawi is predominantly a pediatric disease and scald burns continue to be the most common injury, which is unchanged from previous studies in this country [20,21]. A burn unit in Blantyre, Malawi was established in 1993, and has reported overall mortality between 17 and 25\% $[19,22]$. In their 2003 study, James et al. noted that mortality approached $100 \%$ in patients with burns greater than $30 \%$ TBSA [19]. In contrast, our study population demonstrated $100 \%$ mortality in patients with burns greater than 55\% TBSA. Although the increase in LA50 is encouraging, the limited improvement in overall mortality suggests that only modest improvements have been made in burn care over the past two decades.

The increased survival observed over the past two years is likely due to improved delivery of care within the burn unit. All burn patients are now centralized on one ward and cared for by dedicated staff. The nursing staff and clinical officers serving the unit have received specialized training and, as a result, are able to perform more consistent pain control and wound care. Operative cases have also increased significantly, and patients have access to post-operative physiotherapy, although this service remains limited. Although fluid resuscitation is still not appropriately administered in all cases and operative intervention is often delayed, significant improvements in management have been achieved by consolidating and standardizing the care of burn patients at this hospital.

In order to further improve burn care at $\mathrm{KCH}$, we have developed a standardized burn intake form, which will guide the surgical residents in their initial assessment and treatment of burn patients. We are also working with the nursing staff in the unit to improve documentation of vital signs, urine output, and wound assessments to ensure that patients are monitored appropriately. An operating theater is currently being built within the burn unit at $\mathrm{KCH}$, and we plan to provide specialized training for the anesthetists who will be working in this theater. We hope that these improvements will lead to more appropriate resuscitation, fewer delays in operative intervention, and increased survival for the burn patients in this unit.

Most studies examining mortality from burns have identified three major risk factors associated with increased mortality: age $>60$ years old, TBSA $>40 \%$, and presence of 
inhalation injury [23-26]. Presence of all three risk factors is associated with mortality of $90 \%[23,26]$. Smoke inhalation injury is generally considered to be the strongest predictor of mortality $[23,25]$, but inhalation injuries are relatively uncommon in LMICs compared to high-income countries [1]. The findings from this study confirm the association between increased age, TBSA, and mortality. In this case, TBSA was the strongest predictor of mortality, although other studies have suggested that age greater than 60 years may be a stronger predictor [23]. Given that the life expectancy in sub-Saharan Africa is in the range of $45-53$ years, age greater than 60 years currently has little bearing in survival analysis $[27,28]$.

Burn mortality prediction is particularly important in resource poor settings. Care of severe burns often requires many weeks of intensive care, multiple operative procedures, and months of rehabilitation [29]. A clear understanding of the predictors of mortality in burn patients can help guide surgeons in the appropriate distribution of resources. Over the years, multiple scoring methods of predicting burn survival have been developed [30]. One method is the Baux index, which is the sum of age and TBSA. The higher the Baux index, the higher the mortality and vice versa $[10,31]$. The primary criticisms of the Baux index are that it does not account for inhalation injury and may not reliably represent the risk of small TBSA burns at extremes of age [32]. Alternatively, the Abbreviated Burn Severity Index (ABSI) utilizes age, sex, presence of inhalation injury, and TBSA to calculate a total burn score. A total burn score greater than 10 is associated with less than $40 \%$ survival [30,32]. Neither of these scoring systems account for patient comorbidities or complications that occur during the hospital course.

Despite these limitations, the Baux index or ABSI could be used in the burn unit at $\mathrm{KCH}$. Most patients admitted to this burn unit do not have multiple comorbidities. Likewise, inhalation injury is uncommon in this population, as relatively few fires take place in enclosed, multistory buildings where victims are exposed to prolonged smoke inhalation. As a result, the Baux index and ABSI are appropriate tools in this setting, perhaps more than in high-income countries. The simplicity of these models allows them to be used easily by the clinical staff in the burn unit, who can use the results to guide triage and management of new patients [32].

Mortality from burns remains high in many African countries, despite the well-documented burn management practices employed in developed countries. Reports from hospitals and burn units in Nigeria, Malawi, and South Africa report overall mortality between $12 \%$ and $35 \%$ [18,21-33]. Many factors contribute to the increased mortality in these regions. High rates of poverty, illiteracy, and crowding in urban areas may contribute to unsafe living conditions [14]. Inadequate access to health care facilities often leads to a reliance on traditional medicine and a delay in presentation to the hospital [34,35]. In some cases, patients may present to the hospital only after the burn wounds have become infected, greatly complicating treatment. Designated burn centers and specialized staff are scarce and hospitals are frequently understaffed. In our burn unit, early excision and grafting of burn wounds is often limited by availability of operating rooms, supplies, and personnel [14]. There is a bimodal distribution to burn deaths; early burn mortality is attributable to fluid under-resuscitation, exacerbated by delayed presentation and inadequate supply of intravenous fluids. Those who survive the initial burn shock are left vulnerable to wound infections and ultimately severe sepsis [36]. Many hospitals do not have access to adequate amounts silver nitrate, sulfamylon, antibiotics, or analgesics for appropriate wound care [37]. Patients' recovery may be further complicated by malnutrition and pre-existing illnesses - such as HIV/AIDS, tuberculosis, or malaria [14,37]. As a result, patients with burns exceeding $45 \%$ TBSA rarely survive; patients who do survive are often plagued by scar contractures due to the absence of physical therapy and rehabilitation centers [14]. 
Endeavors at the national level could play a role in reducing burn-related mortality. Malawi, like other African countries, faces unique challenges in burn prevention strategies $[13,17]$. Many families cook over open fires or on unstable cooking stoves, leading to numerous cooking-related burns [14]. Families in the community should be educated regarding fire safety and provided with elevated, stable cooking stoves. Patients with epilepsy are particularly vulnerable to burn, as they often do not have access to appropriate medication $[14,21,38,39]$. Children are most affected by burns and should be the primary focus of prevention strategies [40]. Parents and children should be educated about fire-safety, safe handling and storage of flammable liquids and cooking stoves, and basic first-aid for scald and flame burns. In addition, local and regional health workers should be provided with basic supplies for burn first aid and training to assess burns and appropriately treat and refer patients to the closest burn unit. This could be accomplished through both governmental and non-governmental organizations prioritizing burn prevention programs, supporting existing burn units, and promoting the establishment of new burn units, physical therapy centers, and follow-up burn care centers at both central and district general hospitals.

This study was limited primarily by the available data. Hospital-based data collection is relatively new at this institution [41] and the burn unit had been collecting data on burn patients for just over one year at the time of this study, yielding a modest sample size. In addition, patients with missing data had to be dropped from much of the analysis, further limiting the sample size. The logistic regression analysis represents our best estimate of the true LA50 in this population, but we must acknowledge the limitations of this model, particularly with high TBSA, where the data were sparse. Another major limitation of this study is that burns are not designated as superficial, deep partial thickness, or deep full thickness. Some of the increased mortality associated with flame burns compared to scald burns may be due to differences in burn thickness. Similarly, presence of HIV, malaria, and chronic malnutrition are not being uniformly recorded in this population. These diseases are common in this region and may alter recovery from severe burns $[18,19,39]$, although it is unclear to what extent [42].

This study confirms and expands previous knowledge on the relationship between TBSA and mortality among burn victims, particularly in a resource poor environment. We cannot comment on the role of inhalational injury on mortality in this study as most burn in our environment is outdoors and inhalational injury is rare. This is an important study in our environment as it provides the basis for operational improvements such as aggressive volume resuscitation and early excision and grafting and it provides a template for future quality improvement and outcome measurement.

We anticipate that as burn care and data collection improve at the burn unit at $\mathrm{KCH}$, the LA50 should continue to rise. However, the current lack of resources, operative staff, and hospital personnel, as well as inadequate infrastructure, will continue to pose a significant challenge in this developing nation.

\section{Acknowledgments}

Grant support

This work was supported by the National Institutes of Health Office of the Director, Fogarty International Center, Office of AIDS Research, National Cancer Center, National Heart, Blood, and Lung Institute, the NIH Office of Research for Women's Health through the Fogarty Global Health Fellows Program Consortium comprised of the University of North Carolina, Johns Hopkins, Morehouse, and Tulane (1R25TW009340-01), the American Recovery and Reinvestment Act, and the Fogarty International Center of the National Institutes of Health under Award Number K01TW009486. The content is solely the responsibility of the authors and does not necessarily represent the official views of the National Institutes of Health. 
We thank Johnson and Johnson, the NC Jaycee Burn Center, and the University of North Carolina, Department of Surgery for generous financial support to develop and maintain the burn unit at $\mathrm{KCH}$. We also thank the NC Jaycee Burn Center and Direct Relief International (Santa Barbara, California) for providing burn supplies and the UNC Project for continued administrative support.

Study data were collected and managed using REDCap electronic data capture tools hosted at UNC. ${ }^{1}$ REDCap (Research Electronic Data Capture) is a secure, web-based application designed to support data capture for research studies, providing: (1) an intuitive interface for validated data entry; (2) audit trails for tracking data manipulation and export procedures; (3) automated export procedures for seamless data downloads to common statistical packages; and (4) procedures for importing data from external sources.

\section{References}

1. Forjuoh SN. Burns in low- and middle-income countries: a review of available literature on descriptive epidemiology, risk factors, treatment, and prevention. Burns. 2006; 32:529-37. [PubMed: 16777340]

2. Peck MD, Kruger GE, van der Merwe AE, et al. Burns and fires from non-electric domestic appliances in low and middle income countries. Part I. The scope of the problem. Burns. 2008; 34:303. [PubMed: 18206314]

3. Mathers, C.; Boerma, T.; Fat, DM. The global burden of disease: 2004 update. Geneva: World Health Organization; 2008.

4. Peden, M.; McGee, K.; Sharma, G. The injury chart book: a graphical overview of the global burden of injuries. Geneva: World Health Organization; 2002. p. 27-34.

5. Saffle JR. Predicting outcomes of burns. NEJM. 1998; 338(6):387-8. [Editorial]. [PubMed: 9449735]

6. Kasten KR, Makley AT, Kagan RJ. Update on the critical care management of severe burns. J Intensive Care Med. 2011; 26(4):223-36. [PubMed: 21764766]

7. Church D, Elsayed S, Reid O, et al. Burn wound infections. Clin Microbiol Rev. 2006; 19:403-34. [PubMed: 16614255]

8. Lionelli GT, Pickus EJ, Beckum OK, et al. A three decade analysis of factors affecting burn mortality in the elderly. Burns. 2005; 31:958-63. [PubMed: 16269217]

9. Saffle JR, Davis SH, Williams WP. Recent outcomes in the treatment of burn injury in the United States: a report from the American Burn Association Patient Registry. J Burn Care Rehabil. 1995; 16:219-32. [PubMed: 7673300]

10. Wassermann D, Schlotterer M. Survival rates of patients hospitalized in French burn units during 1985. Burns. 1989; 15(4):261-4. [PubMed: 2765149]

11. Barret JP, Gomez P, Solano I, Gonzalez-Dorrego M, Cristol FJ. Epidemiology and mortality of adult burns in Catalonia. Burns. 1999; 25:325-9. [PubMed: 10431980]

12. Murray, CJL.; Lopez, AD. The global burden of disease: a comprehensive assessment of mortality and disability from diseases, injuries, and risk factors in 1990 and projected to 2020. Switzerland: World Health Organization; 2006.

13. Atiyeh BS, Costagliola M, Hayek SN. Burn prevention mechanisms and outcomes: pitfalls, failures and successes. Burns. 2009; 35:181-93. [PubMed: 18926639]

14. Albertyn R, Bickler SW, Rode H. Paediatric burn injuries in sub-Saharan Africa-an overview. Burns. 2006; 32:605-12. [PubMed: 16713683]

15. Kiser M, Beijer G, Mjuweni S, Muyco A, Cairns B, Charles A. Photographic assessment of burn wounds: a simple strategy in a resource-poor setting. Burns. 2013; 39(1):155-61. [PubMed: 22647494]

16. Samuel JC, Akinkuotu A, Villaveces A, Charles AG, Lee CN, Hoffman IF, et al. Epidemiology of injuries at a Tertiary Care Center in Malawi. World J Surg. 2009; 33:1836-41. [PubMed: 19597877]

${ }^{1}$ Paul A. Harris, Robert Taylor, Robert Thielke, Jonathon Payne, Nathaniel Gonzalez, Jose G. Conde, Research electronic data capture (REDCap) — a metadata-driven methodology and workflow process for providing translational research informatics support, J Biomed Inform; 2009;42(April 2):377-81. 
17. Kiser MM, Samuel JC, McLean SE, Muyco AP, Cairns BA, Charles AG. Epidemiology of pediatric injury in Malawi: burden of disease and implications for prevention. Int J Surg. 2012; 10:611-7. [PubMed: 23142508]

18. Kingu HJ, Mazwai EL. A review of burn care at an emerging centralized burns unit. SAJS. 2010; 48(2):53-8.

19. James J, Hofland HWC, Borgstein ES, Kumiponjera D, Komolafe OO, Zijlstra EE. The prevalence of HIV infection among burn patients in a burns unit in Malawi and its influence on outcome. Burns. 2003; 29:55-60. [PubMed: 12543046]

20. Samuel JC, Campbell ELP, Mjuweni S, Muyco AP, Cairns BA, Charles AG. The epidemiology, management, outcomes, and areas of improvement of burn care in central Malawi: an observational study. J Int Med Res. 2011; 39(3):873-9. [PubMed: 21819720]

21. Komolafe OO, James J, Makoka M, Kalongeolera L. Epidemiology and mortality of burns at Queen Elizabeth Central Hospital Blantyre, Malawi. Cent Afr J Med. 2003; 49(11/12):130-4. [PubMed: 15301466]

22. Stevenson JH, Borgstein E, Van Hasselt E, Falconer I. The establishment of a burns unit in a developing country—a collaborative venture in Malawi. Br J Plast Surg. 1999; 52:488-94. [PubMed: 10673928]

23. Brusselaiers N, Hoste EAJ, Monstrey S, Colpaert KE, De Waele JJ, Vandewoude KH, Blot SI. Outcome and changes over time in survival following severe burns from 1985 to 2004. Intensive Care Med. 2005; 31:1648-53. [PubMed: 16220315]

24. Haik J, Liron A, Tessone A, Givon A, Orenstein A, Peleg K. Burns in Israel: demographic, etiologic and clinical trends, 1997-2003. IMAJ. 2007; 9:659-62. [PubMed: 17939628]

25. Meshulam-Derazon S, Nachumovsky S, Ad-El D, Sulkes J, Hauben DJ. Prediction of morbidity and mortality on admission to a burn unit. Plast Reconstr Surg. 2006; 118(1):116-20. [PubMed: 16816682]

26. Ryan C, Schoenfeld DA, Thorpe WP, Sheridan RL, Cassem EH, Tompkins RG. Objective estimates of the probability of death from burn injuries. NEJM. 1998; 338:362-6. [PubMed: 9449729]

27. Musgrove, P.; Creese, A.; Preker, A.; Baeza, C.; Anell, A.; Prentice, T., et al. The world health report 2000. Geneva: World Health Organization; 2000. Health systems: improving performance; p. $158-9$.

28. National Statistical Office (NSO), ICF Macro. Malawi demographic and health survey 2010. Zomba, Malawi, and Calverton, MD, USA: NSO and ICF Macro; 2011.

29. Mandal A. Quality and cost-effectiveness—effects in burn care. Burns. 2007; 33:414-7. [PubMed: 17467178]

30. Sheppard NN, Hemington-Gorse S, Shelley OP, Philp B, Dziewulski P. Prognostic scoring systems in burns: a review. Burns. 2011; 37:1288-95. [PubMed: 21940104]

31. Papp A. The first 1000 patients treated at Kuopio University Hospital Burn Unit in Finland. Burns. 2009; 35:565-71. [PubMed: 19269102]

32. Pereira C, Murphy K, Herndon D. Outcome measures in burn care: is mortality dead? Burns. 2004; 30:761-71. [PubMed: 15555787]

33. Kalayi GD. Mortality from burns in Zaria: an experience in a developing economy. East Afr Med J. 2006; 83(8):461-4. [PubMed: 17153661]

34. Ndiritu S, Ngumi ZWW, Nyaim O. Burns: the epidemiological pattern, risk, and safety awareness at Kenyatta National Hospital, Nairobi. East Afr Med J. 2006; 83(8):455-60. [PubMed: 17153660]

35. Okoro P, Igwe PO, Ukachukwu AK. Childhood burns in south eastern Nigeria. Afr J Pediatr Surg. $2009 ; 6(1): 24-7$.

36. Komolafe OO, James J, Kalongolera L, Makoka M. Bacteriology of burns at Queen Elizabeth Central Hospital, Blantyre, Malawi. Burns. 2003; 29:235-8. [PubMed: 12706616]

37. Virich G, Lavy CBD. Presentation and management of burn injuries in Malawi. J Wound Care. 2006; 15(7):296-8. [PubMed: 16869196]

38. Buchanan RC. The causes and prevention of burns in Malawi. Cent Afr J Med. 1972; 18(3):55-6. [PubMed: 5024674] 
39. Virich G, Lavy CBD. Burns in Malawi. Ann Burn Fire Disasters. 2006; 19(4):171-3.

40. Burd A, Yuen C. A global study of hospitalized paediatric burn patients. Burns. 2005; 31:432-8. [PubMed: 15896504]

41. Samuel JC, Akinkuotu A, Baloyi P, Villaveces A, Charles A, Lee CN, et al. Hospital-based injury data in Malawi: strategies for data collection and feasibility of trauma scoring tools. Trop Doct. 2010; 40(2):98-9. [PubMed: 20305105]

42. Edge JM, Van der Merwe AE, Pieper CH, Bouic P. Clinical outcomes of HIV positive patients with moderate to severe burns. Burns. 2001; 27:111-4. [PubMed: 11226644] 


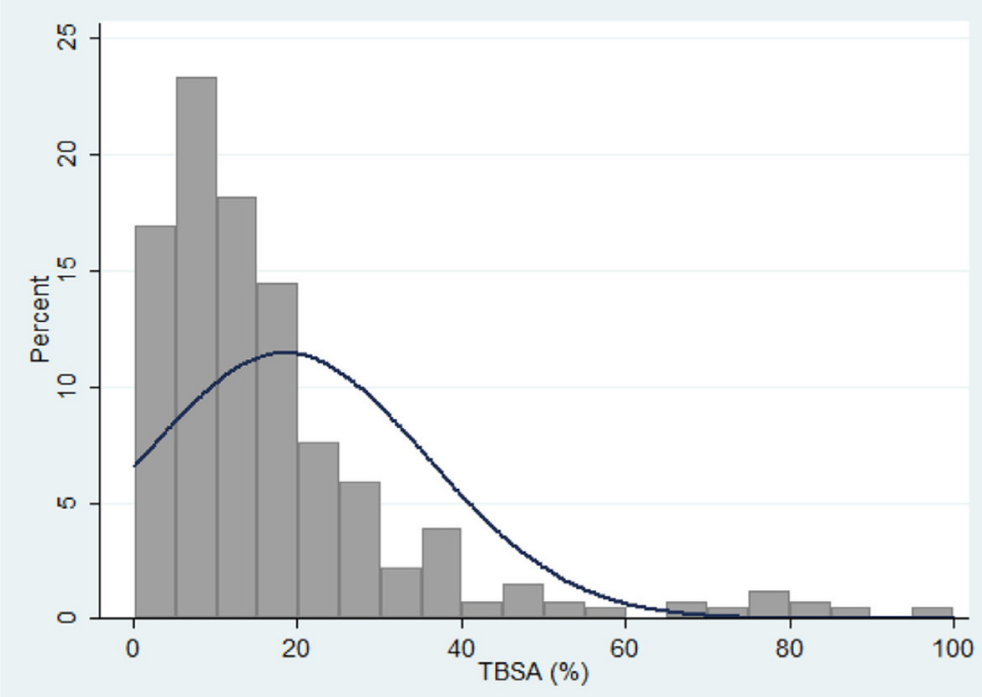

*TBSA $=$ total body surface area $(\%)$

Fig. 1.

Distribution of TBSA* within the study population $(n=408)$. 


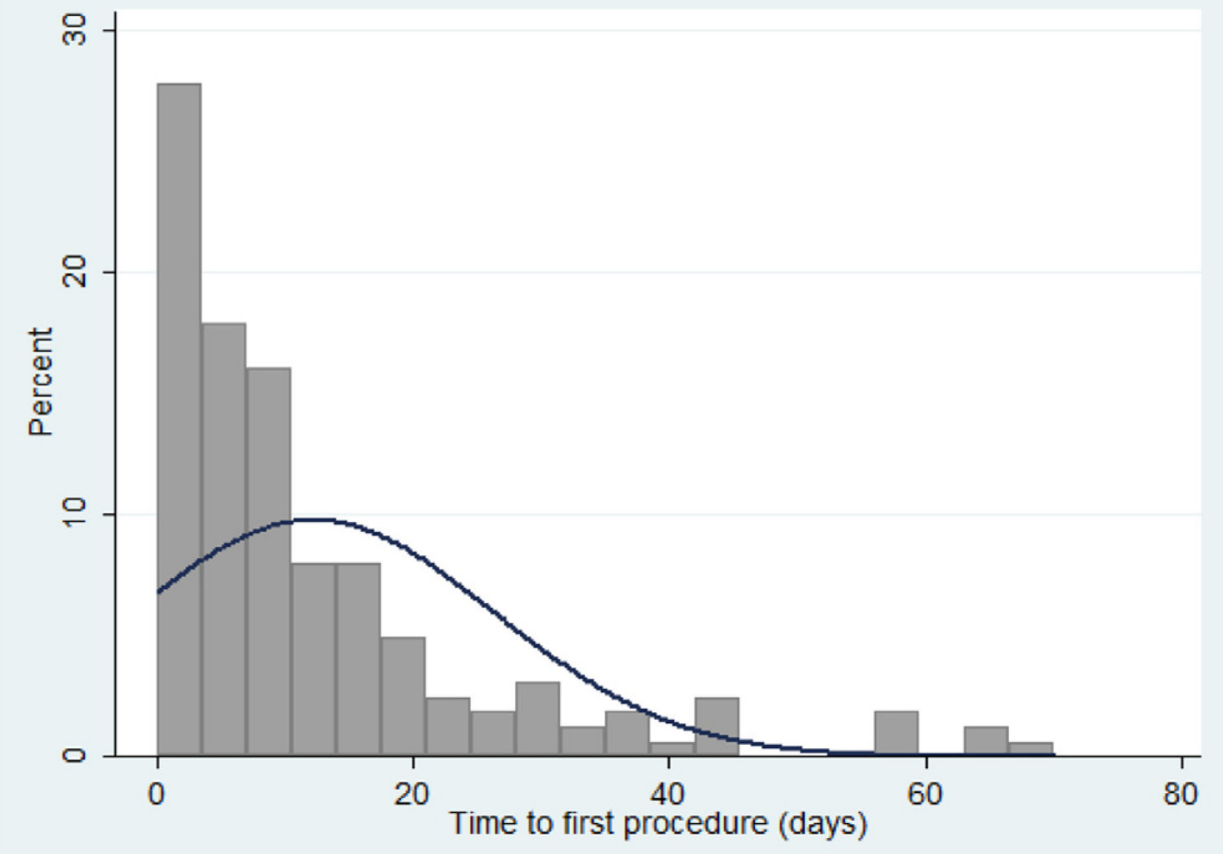

Fig. 2.

Distribution of time from admission to first procedure $(n=162)$. 


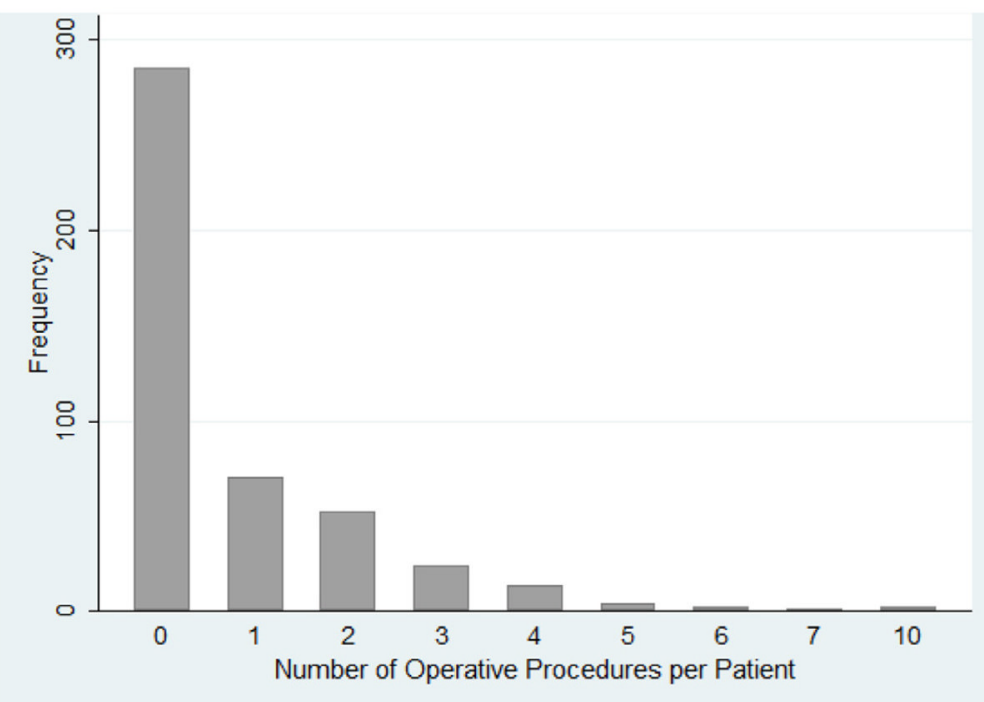

Fig. 3.

Number of operative procedures per patient $(n=454)$. 


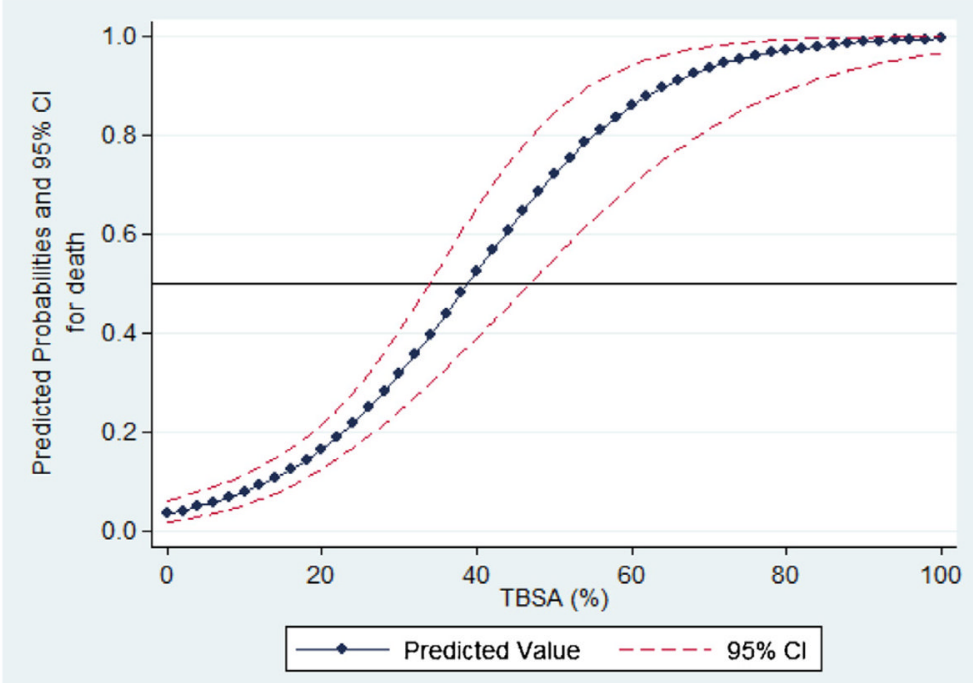

*TBSA $=$ total body surface area (\%)

†Based on a logistic regression model, adjusted for age and mechanism of burn

Fig. 4.

Probability of death by TBSA*, adjusted for age and mechanism of burn ${ }^{\dagger}$. 
Table 1

Patient characteristics.

\begin{tabular}{|c|c|c|}
\hline Patient characteristics $(n=454)$ & $n$ & Mean $( \pm \mathrm{SD})$ or $\%^{b}$ \\
\hline \multicolumn{3}{|l|}{ Sex } \\
\hline Male & 241 & $53 \%$ \\
\hline Female & 208 & $46 \%$ \\
\hline \multicolumn{3}{|l|}{ Age } \\
\hline Mean & & $10.4( \pm 15.1)$ \\
\hline $0-10$ years & 331 & $72.9 \%$ \\
\hline $11-20$ years & 42 & $9.3 \%$ \\
\hline $21-30$ years & 29 & $6.4 \%$ \\
\hline $31-40$ years & 20 & $4.4 \%$ \\
\hline $41-50$ years & 7 & $1.5 \%$ \\
\hline $51-60$ years & 6 & $1.3 \%$ \\
\hline$>60$ years & 11 & $2.4 \%$ \\
\hline \multicolumn{3}{|l|}{ Type of burn } \\
\hline Scald (water) & 176 & $38.7 \%$ \\
\hline Scald (other) & 60 & $13.2 \%$ \\
\hline Flame & 188 & $41.4 \%$ \\
\hline Contact & 7 & $1.5 \%$ \\
\hline Electrical & 4 & $0.9 \%$ \\
\hline \multicolumn{3}{|l|}{$\operatorname{TBSA}^{a}$} \\
\hline Overall mean & 408 & $18.5( \pm 17.4)$ \\
\hline \multicolumn{3}{|l|}{ By sex } \\
\hline Male & 221 & $19.1( \pm 17.9)$ \\
\hline Female & 185 & $17.8( \pm 16.8)$ \\
\hline \multicolumn{3}{|l|}{ By age } \\
\hline $0-18$ years & 325 & $16.8( \pm 14.5)$ \\
\hline $19-60$ years & 69 & $23.5( \pm 22.9)$ \\
\hline$>60$ years & 10 & $40.7( \pm 34.9)$ \\
\hline \multicolumn{3}{|l|}{ Time to presentation to hospital } \\
\hline $0-6 \mathrm{~h}$ & 72 & $18.0 \%$ \\
\hline$>6-12 \mathrm{~h}$ & 82 & $20.5 \%$ \\
\hline$>12-24 \mathrm{~h}$ & 95 & $23.7 \%$ \\
\hline$>24-48 \mathrm{~h}$ & 27 & $6.7 \%$ \\
\hline$>48 \mathrm{~h}$ & 125 & $31.2 \%$ \\
\hline \multicolumn{3}{|l|}{ Survival } \\
\hline Overall mean & 422 & $82.2 \%$ \\
\hline \multicolumn{3}{|l|}{ By sex } \\
\hline Male & 224 & $80.4 \%$ \\
\hline Female & 196 & $84.2 \%$ \\
\hline By age & & \\
\hline
\end{tabular}




\begin{tabular}{lrc}
\hline Patient characteristics $(\boldsymbol{n}=\mathbf{4 5 4})$ & $\boldsymbol{n}$ & Mean $\left( \pm\right.$ SD) or $\boldsymbol{\%}^{\boldsymbol{b}}$ \\
\hline 0-18 years & 339 & $84.1 \%$ \\
19-60 years & 68 & $79.4 \%$ \\
$\quad>60$ years & 11 & $36.4 \%$ \\
\hline$a_{\text {Total body surface area }(\%) .}$ & \\
${ }^{b}$ Category percentages may not add up to $100 \%$ due to missing data.
\end{tabular}




\section{Table 2}

Management of burn patients.

\begin{tabular}{lrr}
\hline Type of management & $\boldsymbol{n}$ & $\boldsymbol{\%}^{\boldsymbol{a}}$ \\
\hline Intravenous fluid resuscitation & & \\
Ordered or administered incorrectly & 38 & 8.4 \\
Not indicated & 47 & 10.4 \\
Late presentation & 63 & 13.9 \\
Ordered correctly & 243 & 53.5 \\
Operative procedure & 360 & \\
Skin graft & 168 & 46.7 \\
Debridement & 154 & 42.8 \\
Escharotomy & 17 & 4.7 \\
Amputation or disarticulation & 6 & 1.7 \\
Trepanation & 7 & 1.9 \\
Contracture release & 5 & 1.4 \\
Other & 3 & 0.8 \\
\hline
\end{tabular}

$a_{\text {Category percentages may not add up to } 100 \% \text { due to missing data. }}$ 
Table 3

Characteristics of patients who survived and patients who died.

\begin{tabular}{|c|c|c|c|c|}
\hline Patient characteristic & $n$ & $\begin{array}{l}\text { Survived to discharge } \\
\text { Mean }( \pm \mathrm{SD}) \text { or } \%\end{array}$ & $\begin{array}{c}\text { Died } \\
\text { Mean }( \pm \text { SD }) \text { or \% }\end{array}$ & $p$-Value ${ }^{b}$ \\
\hline Total number & 454 & 347 & 75 & \\
\hline Sex & & & & 0.3 \\
\hline Male & 224 & $80 \%$ & $20 \%$ & \\
\hline Female & 196 & $84 \%$ & $16 \%$ & \\
\hline Age (years) & 418 & $9.1( \pm 12.9)$ & $15.9( \pm 21.9)$ & 0.0004 \\
\hline $\operatorname{TBSA}^{a}$ & 388 & $14 \%( \pm 9.8)$ & $39 \%( \pm 26.3)$ & $<0.001$ \\
\hline Type of burn & & & & $<0.001$ \\
\hline Scald & 224 & $88 \%$ & $12 \%$ & \\
\hline Flame & 176 & $74 \%$ & $26 \%$ & \\
\hline Time to presentation to hospital & & & & 0.006 \\
\hline $0-6 \mathrm{~h}$ & 68 & $68 \% c$ & $32 \%$ & \\
\hline$>6-12 \mathrm{~h}$ & 77 & $86 \% c$ & $14 \%$ & \\
\hline$>12-24 \mathrm{~h}$ & 90 & $84 \% c$ & $16 \%$ & \\
\hline$>24-48 \mathrm{~h}$ & 26 & $73 \%$ & $27 \%$ & \\
\hline$>48 \mathrm{~h}$ & 120 & $88 \% c$ & $13 \%$ & \\
\hline Time to first procedure (days) & 155 & $12.8( \pm 14.3)$ & $4.8( \pm 4.1)$ & 0.01 \\
\hline Number of operative procedures & & & & 0.272 \\
\hline 0 & 259 & $80 \%$ & $20 \%$ & \\
\hline 1 & 68 & $76 \%$ & $24 \%$ & \\
\hline 2 & 49 & $92 \%$ & $8 \%$ & \\
\hline 3 & 23 & $91 \%$ & $9 \%$ & \\
\hline$\geq 4$ & 23 & $96 \%$ & $4 \%$ & \\
\hline Length of stay (days) & 411 & $25.7( \pm 33.3)$ & $9.4( \pm 11.6)$ & $<0.001$ \\
\hline
\end{tabular}

${ }^{a}$ Total body surface area $(\%)$.

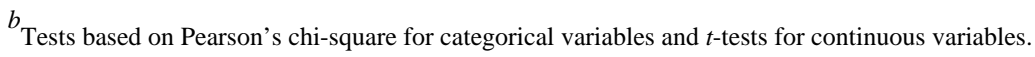

${ }^{c}$ Survival in patients presenting within the first $6 \mathrm{~h}$ is significantly less than survival in patients presenting 6-12, 12-24, or greater than $48 \mathrm{~h}$ after injury $(p<0.01)$. 